\title{
Pustular Rash
}

National Cancer Institute

\section{Source}

National Cancer Institute. Pustular Rash. NCI Thesaurus. Code C90597.

Elevated skin lesions associated with the presence of purulent material. 